\title{
Therapeutic effects of melatonin and quercetin in improvement of hepatic steatosis in rats through supression of oxidative damage
}

\author{
Esrefoglu $\mathrm{M}^{1}$, Cetin $\mathrm{A}^{2}$, Taslidere $\mathrm{E}^{1}$, Elbe $\mathrm{H}^{2}$, Ates $\mathrm{B}^{3}$, Tok $\mathrm{OE}^{1}$, Aydin $\mathrm{MS}^{1}$ \\ Bezmialem Vakif University, Medical Faculty, Dept. of Histology and Embryology, Istanbul, Turkey. \\ drmukaddes@hotmail.com
}

\begin{abstract}
BACKGROUND: Non-alcoholic steatohepatitis, a cause of cirrhosis, is characterized by fatty infiltration of the liver, inflammation, hepatocellular damage and fibrosis. The aim of the present study was to investigate the effects of melatonin and quercetin on CCl4-induced steatosis characterized by fatty infiltration of the liver, inflammation, hepatocellular damage and fibrosis.

METHODS: Rats were divided into 5 groups: Ethanol, Olive oil, CCl4, CCl4+Melatonin (CCl4+Mel), CCl4+Quercetin. Rats were sacrificed and livers were removed for being evaluated by histopathological, immunohistochemical and biochemical methods.

RESULTS: In CCl4 group, vacuolization, vascular congestion, haemorrhage, necrosis, and inflammatory infiltration were identified. The mean tissue MDA level was increased, whereas GSH level and SOD and CAT activities were decreased in comparison with ethanol and olive oil groups. MDA levels were decreased in $\mathrm{CCl} 4+$ Quercetin and $\mathrm{CCl} 4+\mathrm{Mel}$ groups versus $\mathrm{CCl} 4$ group. CAT activity of $\mathrm{CCl} 4+\mathrm{Mel}$ group was higher than that of $\mathrm{CCl} 4$ and $\mathrm{CCl} 4+\mathrm{Quercetin}$ groups. The mean tissue $\mathrm{GSH}$ level of $\mathrm{CCl} 4+\mathrm{Mel}$ group versus $\mathrm{CCl} 4$ group was significantly increased.

CONCLUSIONS: By the means of histopathological examination, we suggest that both agents are beneficial against necrotic and apoptotic cell death during steatosis. Thus, melatonin and quercetin might be beneficial in the improvement of hepatic steatosis by supporting conventional therapy in humans (Tab. 1, Fig. 5, Ref. 53). Text in PDF www.elis.sk.

KEY WORDS: antioxidant, melatonin, quercetin, liver.
\end{abstract}

\section{Introduction}

Non-alcoholic steatohepatitis, a cause of cirrhosis and hepatocellular carcinoma, is characterized by fatty infiltration of the liver, inflammation, hepatocellular damage and fibrosis. Steatosis leads to lipotoxicity, which causes apoptosis, necrosis, generation of oxidative stress and inflammation (1). Hepatocyte apoptosis is an important factor in the development of $\mathrm{CCl}_{4}$ - induced liver toxicity and either precedes the onset of necrosis or coexists with it (2). Carbon tetrachloride $\left(\mathrm{CCl}_{4}\right)$ intoxication results are dependent on dose, steatosis, cirrhosis and hepatoma $(3,4)$.

$\mathrm{CCl}_{4}$-induced liver damage has been extensively studied and widely used as a model for screening hepatoprotectors. It is well established that $\mathrm{CCl}_{4}$ is metabolized in the liver to highly reactive trichloromethyl radical, which initiate free radical-mediated lipid peroxidation of the cytoplasmic membrane phospholipids and causes functional and morphological changes in the cell mem-

${ }^{1}$ Bezmialem Vakif University, Medical Faculty, Dept. of Histology and Embryology, Istanbul, Turkey, ${ }^{2}$ Inonu University, Medical Faculty, Dept. of Histology and Embryology, Malatya, Turkey, and ${ }^{3}$ Inonu University, Faculty of Science and Art, Dept. of Chemistry, Malatya, Turkey

Address for correspondence: M. Esrefoglu, Bezmialem Vakif University, Medical Faculty, Department of Histology and Embryology, Adnan Menderes Bulvari, Vatan cd, 34093, Istanbul, Turkey.

Phone: +90.5323465239 , Fax: +90.2125336855 brane leading to accumulation of lipid-derived oxidants causing liver injury $(5,6)$.

Oxidative stress occurs as the result of the insufficient protective capacity of cellular antioxidant enzyme system against increased production of reactive oxygen species (ROS), which react with almost all cellular biomolecules such as: lipids, nucleic acid and proteins, changing their structure and thus their function, which leads to cell damage. Organisms widely use glutathione (GSH), glutathione peroxidase (GSH-Px), superoxide dismutase (SOD), catalase (CAT), and a variety of other antioxidants to protect themselves against generation of ROS. In recent years, substantial amounts of data about the efficiency of antioxidant agents against oxidative damage have been obtained from experiments with rodents. For assessment of biological effects of ROS, the tissue levels of malondialdehyde (MDA), as indicator of lipid peroxidation, and the levels/activities of antioxidant enzymes including SOD, GSH, GSH-Px, and CAT are useful. In the present study, we detected tissue MDA and GSH levels and SOD and CAT activities in addition to histopathological examination in the evaluation of the effects of melatonin and quercetin against $\mathrm{CCl}_{4}$-induced hepatitis steatosis. Additionally, we evaluated the number of apoptotic cells as well as proliferating cells in order to determine tissue damage versus tissue regeneration.

As the oxidative stress is a common pathogenetic mechanism contributing to initiation and progression of stress-induced organ 
injury, antioxidants represent a logical therapeutic and preventive strategy for the treatment of the stress-induced organ damage. Many natural compounds have the ability to scavenge ROS, thereby reducing oxidative stress directly, or they may offer an indirect protection by activating endogenous defence systems. In fact, induction of enzymes relevant in cell defence system seems conceivable.

Melatonin is a direct scavenger of free radicals and the most powerful known antioxidant. It exerts its protective effects by increasing antioxidant enzyme levels/activities (7-11) or inhibiting pro-oxidative enzymes via its action on melatonin receptor (12, 13). The quercetin $\left(3,5,7,3\right.$ ', $4^{\prime}$ '-pentahydroxiflavon), one of the well-recognized flavonoids, is also a potent antioxidant (14). Flavonoids are primarily found in vegetables, fruits, red wine, green tea, and onion (15). Herein, we tried to investigate the effects of melatonin and quercetin, two powerful antioxidant agents, on $\mathrm{CCl}_{4}$-induced steatohepatitis.

\section{Materials and methods}

\section{Animals and experimental protocol}

Thirty-five female Wistar albino rats (3-4 months old) weighing 220-240 g obtained from the Experimental Animal Research Center of Inonu University were used in the present study. The animals were housed in individual cages for 10 days in a well -ventilated room with a 12: 12 -hour light/dark cycle at $21^{\circ} \mathrm{C}$. Animals were fed with standard rat chow and tap water ad libitum. The experiments were performed in accordance with the Guidelines for Animal Research from National Institute of Health and were approved by the Committee on Animal Research at Inonu University, Malatya, Turkey.

Rats were divided into 5 groups, each containing 7 rats as follows: Ethanol group: (administered by $5 \%$ ethanol, $1 \mathrm{ml} / \mathrm{day} / \mathrm{ip}$ ), Olive oil group (administered by olive oil, $0.5 \mathrm{ml} /$ every other day/ ip), $\mathrm{CCl}_{4}$ group (administered by $0.5 \mathrm{ml} / \mathrm{kg} \mathrm{CCl}_{4}$ dissolved in 0.5 $\mathrm{ml} / \mathrm{kg}$ olive oil, for 10 days/every other day/ip), $\mathrm{CCl}_{4}+$ Melatonin $\left(\mathrm{CCl}_{4}+\mathrm{Mel}\right)$ (administered by $10 \mathrm{mg} / \mathrm{kg} / \mathrm{day} / \mathrm{ip}$. melatonin dissolved in $5 \%$ ethanol, injected 24 hours after administrations of $\mathrm{CCl}_{4}$, for 10 days), $\mathrm{CCl}_{4}+$ Quercetin $\left(\mathrm{CCl}_{4}+\right.$ Quer) group (administered by $25 \mathrm{mg} / \mathrm{kg} /$ day/ip. quercetin dissolved in $5 \%$ ethanol, injected 24 hours after administrations of $\mathrm{CCl}_{4}$ for 10 days). 24 hours after the last dose of $\mathrm{CCl}_{4}$ at 10 th day, rats were sacrificed by ketamine anaesthesia and livers were removed and divided into two portions. One part of the samples was used for histopathological examination, whereas the other was used for evaluation of the oxidative stress parameters by biochemical methods.

\section{Histopathological evaluation}

The liver tissues fixed in $10 \%$ formalin for $24 \mathrm{~h}$ were embedded in paraffin. Tissue sections cut at $5 \mu \mathrm{m}$ stained with haematoxylin-eosin (H-E) method. Samples were examined using a Leica DFC280 light microscope and a Leica Q Win Image Analysis system (Leica Micros Imaging Solutions Ltd., Cambridge, UK). Assessment of tissue alterations in 20 different fields for each section was conducted by an experienced histologist, who was unaware of the treatment. Under 10X magnification, sections were examined for the alterations including vacuolization, vascular congestion, haemorrhage, inflammatory infiltration and necrosis. Each alteration was scored as followed: $0=$ normal, $1=$ mild, $2=$ moderate and $3=$ severe, with a maximum score of 15 .

\section{TUNEL method for detecting apoptosis}

TUNEL method was used in accordance with the user's manual of the manufacturer (Apoptag plus Peroxidase in situ Apoptosis Kit, Chemicon International, Cat: S7101). The procedure was following: Sections were incubated with proteinase K for $5 \mathrm{~min}$, washed with distilled water and incubated with $3 \%$ hydrogen peroxide in PBS for 5 min. Later, sections were washed with PBS, put in the equilibrium buffer for $30 \mathrm{~min}$ and incubated in TdT enzyme at $37^{\circ} \mathrm{C}$ for 1 hour. They were agitated in washing buffer for $15 \mathrm{~s}$, washed in PBS, put into anti-digoxigenin conjugate for $30 \mathrm{~min}$ and then washed with PBS. After incubation with peroxidase for $6 \mathrm{~min}$, they were washed with destilled water, stained with Mayer's haematoxylin and covered with mounting medium. In each section, TUNEL positive cells on 20 similar areas were counted under 20X magnification.

\section{Proliferating cell nuclear antigen (PCNA) staining}

Cell proliferation analysis was performed on paraffin-embedded sections using the PCNA Staining Kit (Invitrogen, Cat: 931143) following the manufacturer's protocol. Paraffin-embedded liver sections were dewaxed by treating the slides in 2 changes of xylene for 5 minutes each and were rehydrated. Endogenous peroxidase activity was quenched by using $3 \%$ hydrogen peroxide in PBS for $20 \mathrm{~min}$. The slides were incubated with ready-to-use blocking solution for 10 minutes and then incubated with biotinylated monoclonal anti-PCNA antibody (ready-to-use) for 1 hour. After washing, sections were incubated with Streptavidin-Peroxidase (ready-to-use) for 10 minutes at room temperature, followed by incubation with 3, 3'-diaminobenzidine (DAB) for 5 minutes. Slides were finally counterstained with Mayer's haematoxylin and covered with mounting medium. Number of cells expressing PCNA was counted on 10 representative fields under $20 \mathrm{X}$ magnification.

\section{Analysis of tissue regeneration versus apoptosis status}

We calculated the tissue regeneration index (TRI) by dividing the mean PCNA positive cells to the mean TUNEL positive cells of each groups. Higher index value showed us a higher number of proliferating cells and/or fewer number of apoptotic cells.

\section{Biochemical evaluation}

Preparation of Tissue Homogenates: Tissues were homogenized (PCV Kinematica Status Homogenizator) in ice-cold phosphate buffered saline ( $\mathrm{pH}$ 7.4). The homogenate was sonified with an ultrasonifier (Bronson sonifier 450 ) by 3 cycles ( 20 -s sonications and 40-s pause on ice). The homogenate was centrifuged (15,000 $\mathrm{xg}, 10 \mathrm{~min}, 4^{\circ} \mathrm{C}$ ) and cell-free supernatant was subjected to enzyme assay immediately.

Determination of Protein: Protein levels of the tissue samples were measured by the Bradford method (16). The absorbance mea- 
surement was taken at $595 \mathrm{~nm}$ using a UV-VIS spectrophotometer. Bovine serum albumin (BSA) was used as protein standard.

Determination of Malondialdehyde levels: The analysis of lipid peroxidation was carried out as described (17) with a minor modification. The reaction mixture was prepared by adding $250 \mu \mathrm{L}$ homogenate into $2 \mathrm{ml}$ reaction solution ( $15 \%$ trichloroacetic acid: $0.375 \%$ thiobarbituric acid: $0.25 \mathrm{~N} \mathrm{HCl}, 1: 1: 1, \mathrm{w} / \mathrm{v})$ and heated at $100{ }^{\circ} \mathrm{C}$ for $15 \mathrm{~min}$. The mixture was cooled to room temperature, centrifuged ( $10.000 \mathrm{~g}$ for $10 \mathrm{~min}$ ) and the absorbance of the supernatant was recorded at $532 \mathrm{~nm}$. 1,1,3,3-tetramethoxypropane was used as MDA standard. MDA results were expressed as nmol/ $\mathrm{mg}$ protein in the homogenate.

Determination of Glutathione Levels: The formation of 5-thio2-nitrobenzoate (TNB) is followed spectrophotometrically at 412 $\mathrm{nm}$ (18). The amount of GSH in the extract was determined as $\mathrm{nmol} / \mathrm{mg}$ protein utilizing a commercial GSH as the standard.

Measurement of Catalase Activities: CAT activity was measured at $37^{\circ} \mathrm{C}$ by following the rate of disappearance of hydrogen peroxide $\left(\mathrm{H}_{2} \mathrm{O}_{2}\right)$ at $240 \mathrm{~nm}\left(\varepsilon_{240}=40 \mathrm{M}^{-1} \mathrm{~cm}^{-1}\right)$ (19). One unit of catalase activity is defined as the amount of enzyme catalysing the degradation of $1 \mu \mathrm{mol}$ of $\mathrm{H}_{2} \mathrm{O}_{2}$ per min at $37^{\circ} \mathrm{C}$ and specific activity corresponding to transformation of substrate (in $\mu \mathrm{mol}$ ) $\left(\mathrm{H}_{2} \mathrm{O}_{2}\right)$ per min per mg protein. The activity of CAT was determined as U/mg protein.

Measurement of Superoxide Dismutase (SOD) Activities: SOD $(\mathrm{Cu}, \mathrm{Zn}-\mathrm{SOD})$ activity in the supernatant fraction was measured using xanthine oxidase/cytochrome c method (20), where 1 unit (U) of activity is the amount of enzyme needed to cause half-maximal inhibition of cytochrome $\mathrm{c}$ reduction. The amount of SOD in the extract was determined as $\mathrm{U} / \mathrm{mg}$ protein, utilizing a commercial SOD as the standard.

\section{Statistical evaluations}

Statistical analysis was carried out using the SPSS for Windows version 13.0 (SPSS Inc., Chicago, III., USA) program. All data are expressed as the arithmetic mean \pm Standard error (SE). Normality for continued variables in groups was determined by the Shapiro Wilk test. Since the variables of biochemical results did not show a normal distribution $(\mathrm{p}<0.05)$, Kruskal-Wallis and Mann Whitney U tests were used for the comparison of variables among the studied groups. For histopathological evaluation, data were obtained from TUNEL and PCNA analysis, one-way analysis of variance (ANOVA) test was used. The $p<0.05$ was regarded as significant.
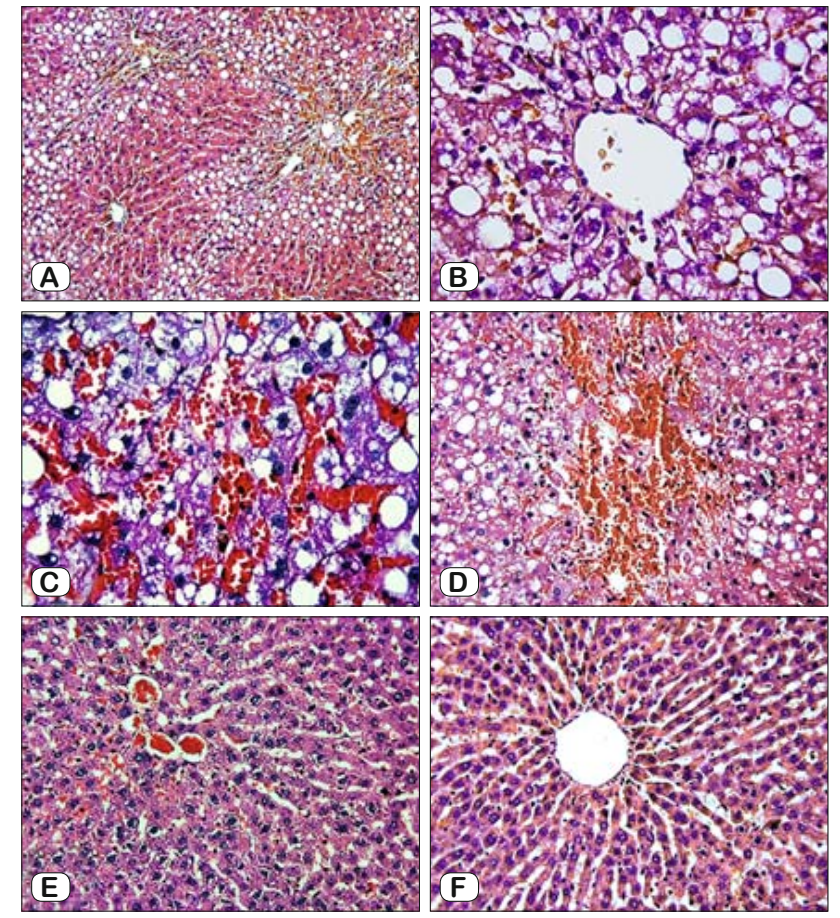

Fig. 1. Massive steatosis, haemorrhage and necrosis are seen in the liver section of a rat from $\mathrm{CCl}_{4}$ group, $\mathrm{x10}$ (A). Many intracytoplasmic vacuoles of various sizes are obvious in the liver section of a rat from $\mathrm{CCl}_{4}$ group, $\mathrm{x} 40$ (B). Steatosis and congestion are seen within hepatocyte cytoplasm in the liver section of a rat from $\mathrm{CCl}_{4}$ group, $\mathrm{x40}$ (C). Steatosis, haemorrhage and necrosis are observed in the liver section of a rat from $\mathrm{CCl}_{4}$ group, $\mathrm{x} 40$ (D). Histopathological picture of the liver section of a rat from $\mathrm{CCl}_{4}+\mathrm{Mel}$ group, $\mathrm{X} 20$ (E). Histopathological picture of the liver section of a rat from $\mathrm{CCl}_{4}+\mathrm{Quer}$ group, $\mathrm{x} 20$ (F).

\section{Results}

Liver of ethanol and olive oil groups were normal in histological appearance. In $\mathrm{CCI}_{4}$ group, vacuolization (Figs 1A-D), vascular congestion (Fig. 1C), haemorrhage, necrosis (Figs 1A, 1D), and inflammatory infiltration were identified mainly in the central to middle part of hepatic lobule. $\mathrm{CCl}_{4}$ administration resulted in severe steatosis. Numerous 'ballooning' cells grouped so that separate zones of liver parenchyma, giving an appearance of 'Swiss cheese' were observed (Figs 1A-B). The histopathological alterations including mainly steatosis were apparently proved in $\mathrm{CCI}_{4}+\mathrm{Mel}$ and $\mathrm{CCI} 4+$ Quer groups (Figs $1 \mathrm{E}, 1 \mathrm{~F}$; respectively)

Tab. 1. Mean MHDSs, mean tissue MDA and GSH levels and SOD and CAT activities of all groups.

\begin{tabular}{|c|c|c|c|c|c|}
\hline Groups & MHDSs & $\begin{array}{c}\text { MDA } \\
\text { (nmol/mg pr) }\end{array}$ & $\begin{array}{c}\text { SOD } \\
\text { (U/mg pr) }\end{array}$ & $\begin{array}{c}\text { CAT } \\
\text { (U/mg pr) }\end{array}$ & $\begin{array}{c}\text { GSH } \\
\text { (nmol/g pr) }\end{array}$ \\
\hline Ethanol & $0.57 \pm 0.53$ & $0.16 \pm 0.01$ & $7.94 \pm 0.36$ & $121.05 \pm 8.72$ & $4.18 \pm 0.31$ \\
\hline Olive oil & $0.28 \pm 0.48$ & $0.26 \pm 0.02$ & $8.89 \pm 0.45$ & $118.29 \pm 8.93$ & $3.97 \pm 0.45$ \\
\hline $\mathrm{CCl}_{4}$ & $12.00 \pm 1.00^{\mathrm{a}, \mathrm{b}}$ & $0.56 \pm 0.04^{\mathrm{d}, \mathrm{e}}$ & $7.08 \pm 0.38^{f}$ & $62.36 \pm 5.91^{\mathrm{d}, \mathrm{e}}$ & $1.78 \pm 0.16^{\mathrm{d}, \mathrm{e}}$ \\
\hline $\mathrm{CCl}_{4}^{4}+\mathrm{Mel}$ & $1.71 \pm 1.11^{\mathrm{c}}$ & $0.41 \pm 0.02^{\mathrm{d}, \mathrm{f}, \mathrm{g}}$ & $7.96 \pm 0.46$ & $94.2 \pm 8.65^{\mathrm{j}, \mathrm{k}, \mathrm{l}}$ & $2.72 \pm 0.29^{\mathrm{n}, \mathrm{p}, \mathrm{r}}$ \\
\hline $\mathrm{CCl}_{4}^{4}+$ Ouer & $4.00 \pm 1.82^{c}$ & $0.23 \pm 0.02^{\mathrm{h}}$ & $7.88 \pm 0.31$ & $66.02 \pm 4.48^{\mathrm{d}, \mathrm{e}, \mathrm{m}}$ & $2.69 \pm 0.29^{\mathrm{s}, \mathrm{t}}$ \\
\hline
\end{tabular}

${ }^{\mathrm{a}} \mathrm{p}=0.0001 \mathrm{vs}$ Ethanol, ${ }^{\mathrm{b}} \mathrm{p}=0.0001$ vs Olive oil, ${ }^{\mathrm{c}} \mathrm{p}=0.0001 \mathrm{vs} \mathrm{CCl}_{4},{ }^{\mathrm{d}} \mathrm{p}=0.0000$ vs Ethanol, ${ }^{\mathrm{e}} \mathrm{p}=0.0000$ vs Olive oil, ${ }^{\mathrm{f}} \mathrm{p}=0.0002$ vs Olive oil, ${ }^{\mathrm{g}} \mathrm{p}=0.0002$ vs CCl ${ }_{4},{ }^{\mathrm{h}}$

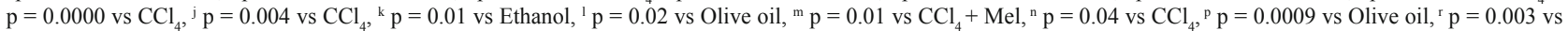
Ethanol, ${ }^{\mathrm{s}} \mathrm{p}=0.002$ vs Ethanol, ${ }^{\mathrm{t}} \mathrm{p}=0.008$ vs Olive oil 

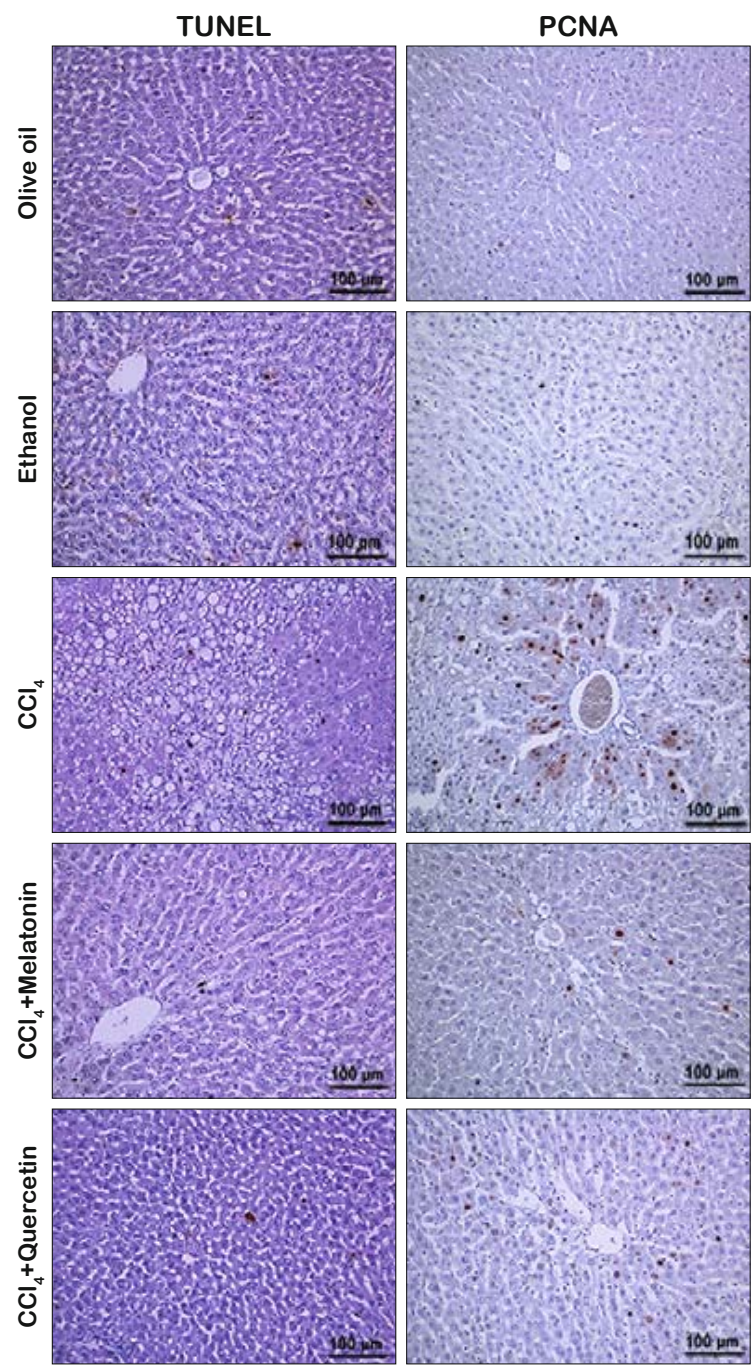

Fig. 2. TUNEL positive and PCNA positive hepatocytes are observed in the sections from the groups.

with occasional areas showed lipid vacuolization and vascular congestion. Mean histopathological damage scores (MHDSs) were $0.57 \pm 0.53$ in ethanol, $0.28 \pm 0.48$ in olive oil, $12.00 \pm 1.00$ in $\mathrm{CCI}_{4}, 1.71 \pm 1.11$ in $\mathrm{CCI}_{4}+\mathrm{Mel}$ and $4.00 \pm 1.82$ in $\mathrm{CCI}_{4}+$ Quer groups. MHDSs of $\mathrm{CCI}_{4}$ group was significantly higher than those of ethanol and oil groups $(\mathrm{p}=0.0001)$. MHDSs of $\mathrm{CCI}_{4}+\mathrm{Mel}$ and CCI4+Quer groups were significantly lower than that of $\mathrm{CCI}_{4}$ group, but significantly higher than that of ethanol and oil groups $(p=0.0001)$. The severity of tissue damage in $\mathrm{CCI}_{4}+$ Quercetin group was higher than $\mathrm{CCI}_{4}+\mathrm{Mel}$ group suggesting that melatonin provided a higher protection than quercetin. MHDSs of all groups are summarized in the Table 1.

$\mathrm{CCI}_{4}$ administration resulted in significant increases in the numbers of the cells undergoing both proliferation and apoptosis. The mean PCNA positive cell numbers of ethanol, olive oil, $\mathrm{CCI}_{4}$, $\mathrm{CCI}_{4}+\mathrm{Mel}$ and $\mathrm{CCI}_{4}+$ Quer groups were $23.5 \pm 9.07,25 \pm 3.16,796$ $\pm 99.8,180 \pm 66$ and $128 \pm 41.3$; respectively. The mean TUNEL positive cell numbers of ethanol, olive oil, $\mathrm{CCI}_{4}, \mathrm{CCI}_{4}+\mathrm{Mel}$ and

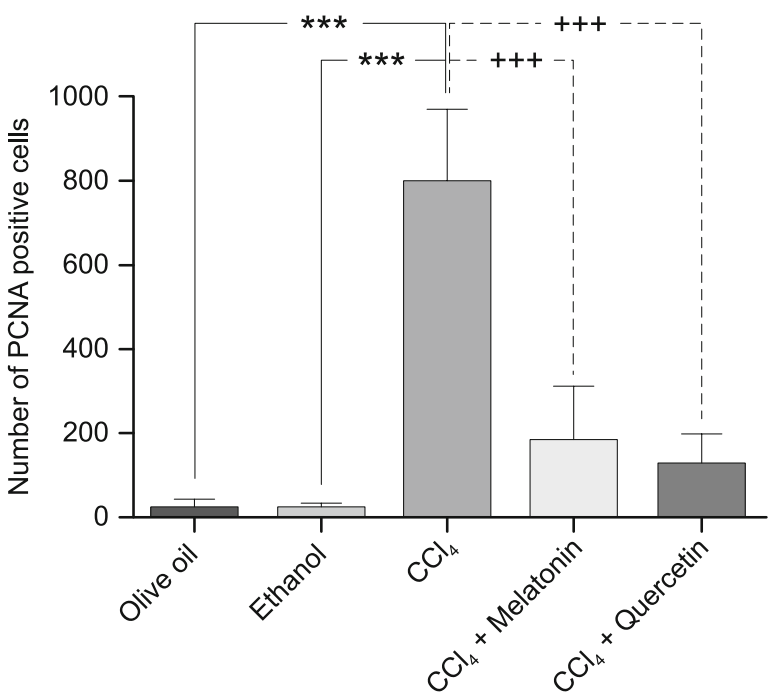

Fig. 3. The mean numbers of PCNA positive hepatocytes from all of the groups. ${ }^{* * *} \mathbf{p}<0.0001$ vs olive oil and ethanol groups; ${ }^{+++} \mathbf{p}<0.0001$ vs $\mathrm{CCl}_{4}+\mathrm{Mel}$ and $\mathrm{CCl}_{4}+$ Quer groups.

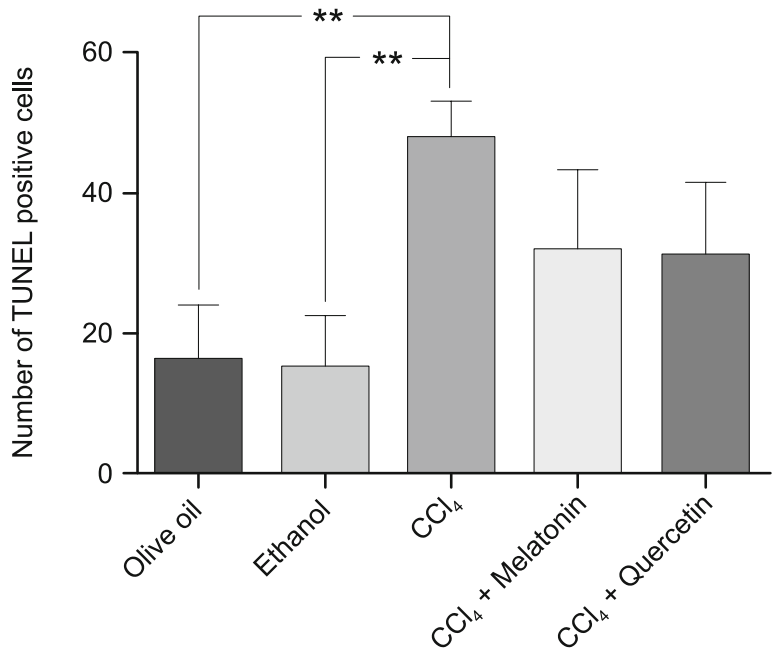

Fig. 4. The mean numbers of PCNA positive hepatocytes from all of the groups. $* * * \mathbf{p}<0.001$ vs olive oil and ethanol groups.

$\mathrm{CCI}_{4}+$ Quer groups were $16.25 \pm 3.75,15 \pm 4.35,47.75 \pm 2.75$, $31.8 \pm 5.12$ and $31 \pm 4.66$; respectively. The mean PCNA positive cell number in $\mathrm{CCI}_{4}$ administered group was significantly higher than those of ethanol, olive oil, $\mathrm{CCI}_{4}+\mathrm{Mel}$ and CCI4+Quer groups $(\mathrm{p}<0.001)$ (Figs 2, 3). The mean TUNEL positive cell number in $\mathrm{CCI}_{4}$ administered group was also significantly higher than those of ethanol and olive oil groups $(\mathrm{p}<0.01)$. Melatonin and quercetin administration reduced apoptosis; however, significant importance was not detected among the groups (Figs 2, 4). Additionally, the mean TRI of ethanol, olive oil, $\mathrm{CCI}_{4}, \mathrm{CCI}_{4}+\mathrm{Mel}$ and $\mathrm{CCI}_{4}+$ Quer groups were 1.44, 1.68, 16.67, 5.65, 4.12; respectively (Fig. 5).

In $\mathrm{CCI}_{4}$ group, the mean tissue MDA level was increased, whereas GSH level and SOD and CAT activities were decreased significantly in comparison with ethanol and/or olive oil groups. 


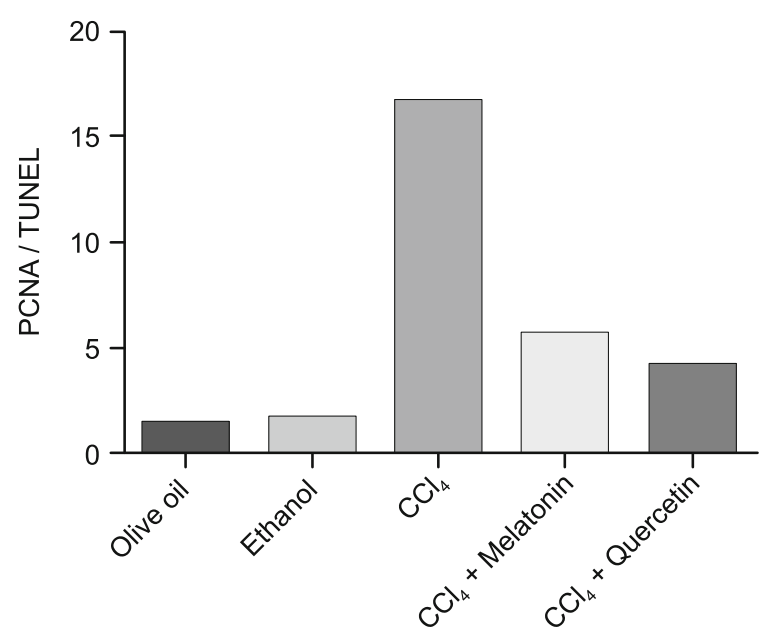

Fig. 5. TRIs of all of the groups.

However, MDA level was decreased in the $\mathrm{CCI}_{4}+$ Quercetin and $\mathrm{CCI}_{4}+\mathrm{Mel}$ groups, when compared with the $\mathrm{CCI}_{4}$ group ( $p=0.0002, p=0.000 ;$ respectively). The mean tissue CAT $(\mathrm{p}=0.0000)$ and SOD $(\mathrm{p}=0.0002)$ activity were decreased in $\mathrm{CCI}_{4}$ group versus ethanol/olive oil groups. CAT activity of $\mathrm{CCI}_{4}+\mathrm{Mel}$ group was higher than that of $\mathrm{CCI}_{4}(\mathrm{p}=0.004)$ and $\mathrm{CCI}_{4}+$ Quercetin $(\mathrm{p}=0.01)$ groups. The mean tissue GSH level of $\mathrm{CCI}_{4}$ group versus ethanol/olive oil groups was significantly decreased $(p=0.000)$, whereas the mean tissue GSH level of $\mathrm{CCI}_{4}+\mathrm{Mel}$ group versus $\mathrm{CCI}_{4}$ group was significantly increased $(\mathrm{p}=0.04)$. Although GSH level of $\mathrm{CCI}_{4}+$ Quercetin group was lower than that of $\mathrm{CCI}_{4}$ group, quercetin administration had no statistically significant effect on the mean tissue GSH level. These results indicated that melatonin and quercetin were able to inhibit lipid peroxidation and the production of MDA, and stimulate the production of antioxidant enzymes. In regard to the results of antioxidant enzymes, it seems that melatonin is more effective than quercetin in the treatment of hepatic steatosis. The mean tissue MDA and GSH levels and CAT activities of all groups are summarized in Table 1.

\section{Discussion}

In the present study, rats were administered $\mathrm{CCl}_{4}$ by oral route to prepare hepatic steatosis model. Administration of $\mathrm{CCl}_{4}$ to rats was shown to cause oxidative stress in liver and oxidative damage was associated with a significantly higher level of MDA, but lowered the activities of antioxidant enzymes; CAT, SOD, and level of GSH. Increased MHDs and MDA levels in $\mathrm{CCI}_{4}$ administered rats indicated that liver architecture was damaged.

The histological evidence induced by $\mathrm{CCl}_{4}$ is known as hepatocellular necrosis, fatty changes, ballooning degeneration, and mononuclear cell infiltration (21). Long-term administration of $\mathrm{CCl}_{4}$ causes chronic liver injury, and is a widely accepted model to produce hepatic fibrosis $(22,23)$. Our microscopic examination revealed that $\mathrm{CCI}_{4}$ administration resulted in necrosis and severe steatosis. By melatonin and quercetin administration, histopathological picture of livers was relieved.

It has been known for a long time that a part of the liver injury caused by $\mathrm{CCl}_{4}$ may have originated through the free radical reactions to the metabolism of $\mathrm{CCl}_{4}$ in the liver and subsequent initiation of lipid peroxidation (24). Liver injuries induced by $\mathrm{CCl}_{4}$ are mediated through the formation of reactive intermediates such as trichloromethyl radical $(\mathrm{CCl} 3 \bullet)$ and its derivative trichloromethyl peroxy-radical $(\mathrm{CCl} 3 \mathrm{OO} \bullet$ ), generated by cytochrome $\mathrm{P} 450$ of liver microsomes (25). These highly reactive derivatives interact with membrane lipids leading to their peroxidation, which produces MDA as the final product along with other metabolites (26). Membrane disintegration, loss of membrane-associated enzymes $(27,28)$ and necrosis are some of the consequences of $\mathrm{CCl}_{4}$-induced lipid peroxidation.

ROS play important roles in apoptosis initiated in mitochondria $(29,30)$. It has been reported that GSH suppression and MDA increase are inducers of mitochondrial permeability transition (31). Leading to the release of several different factors relevant to apoptosis (32). Significant increases in the amounts of carious caspase types including caspase 3 and caspase 8 were observed when the hepatocytes were exposed to $\mathrm{CCl}_{4}$ (33). We detected a significant increase in TUNEL positive, as well as, PCNA positive cell numbers in $\mathrm{CCl}_{4}$ administered group. Liver has a high capacity to regenerate itself under the inducing effects of various factors including oxidative stress. Following any injury, hepatocytes can maintain regeneration by rapid proliferation. DNA synthesis has been shown to peak in the first 40-44 hours after partial hepatectomy (34). Hepatocytes are capable to reform the hepatic architecture by 69 successive divisions (35). We suggest that increased number of PCNA positive cells represents $\mathrm{CCl}_{4}$-induced proliferative activity of the hepatocytes. Thus, the highest number of TUNEL positive cells was detected in this group.

Müller et al (36) stated that $\mathrm{CCl}_{4}$ intoxication was similar to the hepatitis in case of the triglycerides catabolism. This situation could be also attributed to the reduction of lipase activity, which could lead to decrease in triglyceride hydrolysis (37). On the other hand, it can be assumed that hypercholesterimea in $\mathrm{CCl}_{4}$ intoxicated rats has resulted in damage of hepatic parenchyma cells that lead to disturbance of lipid metabolism in liver (38).

Organisms are well protected against the free radical damages by their own endogenous antioxidants, which are either antioxidant enzymes such: SOD and CAT or organic chemical compounds such as: ascorbic acid, tocopherols and GSH. The coordinate action of antioxidant system is very critical for the detoxification of free radicals. GSH is supposed to be a highly effective extra-and intracellular antioxidant compound that neutralizes hydrogen peroxide and hydroperoxide by its scavenging and antioxidant properties. SOD reduces the concentration of highly reactive superoxide radical by converting it to $\mathrm{H}_{2} \mathrm{O}_{2}$, whereas CAT decomposes $\mathrm{H}_{2} \mathrm{O}_{2}$ and protect the tissues from highly reactive hydroxyl radicals (39). SOD and CAT are the major antioxidant enzymes responsible for the elimination of ROS. These enzymes are highly sensitive to lipid peroxide or ROS $(40,41)$. This may account for the much lower SOD and CAT activities in the liver of the $\mathrm{CCl}_{4}$-treated rats relative to the normal healthy rats. 
$347-354$

Melatonin is not only a direct antioxidant, but also an indirect antioxidant through enhancement of antioxidant enzyme activities in liver (42). In the present study, melatonin was found to be more beneficial than expected on hepatic steatosis. While the microscopic sections of rats administered $\mathrm{CCl}_{4}$ were full of vacuolated hepatocytes, we randomly saw such hepatocytes in sections from melatonin treated rats. Moreover, MHDS and MDA levels of $\mathrm{CCl}_{4}+\mathrm{Mel}$ group were significantly lower than that of $\mathrm{CCl}_{4}$ group. As expected, melatonin supported cellular antioxidant defense system by increasing mainly the hepatic CAT activity and GSH level. Recently, Talu et al (43) also found melatonin at a dose of $20 \mathrm{mg} /$ $\mathrm{kg}$ /day melatonin was effective in acute and chronically administered $\mathrm{CCl}_{4}$-induced hepatic damage including hepatic steatosis. Kus et al (44) also found melatonin effective at the dose of $25 \mathrm{mg} /$ $\mathrm{kg}$ for 1 month in healing of $\mathrm{CCl}_{4}$-induced liver damage including necrosis, fibrosis, mononuclear cell infiltration, and fatty degeneration. They reported a normal lobular appearance except for a mild hydropic degeneration of hepatocytes in melatonin-administered group. Similar to their results, histological picture of the sections from $\mathrm{CCl}_{4}+\mathrm{Mel}$ was nearly normal in our study. Additionally, we detected decreased numbers of PCNA and TUNEL positive cells in melatonin administered group versus $\mathrm{CCl}_{4}$ administered group. It is clear that melatonin is beneficial against necrotic as well as apoptotic cell death. On the other hand, we suggest that decrease in the number of PCNA positive cells resulted in the improvement of inducing effect such as: oxidative stress rather than a failure in the proliferative capacity of hepatocytes. A few recent studies on high fat diet-induced fatty liver disease agreed that melatonin is a potent therapeutic agent against steatosis $(45,46)$. Pan et al $(46)$ reported that melatonin reduced liver total cholesterol and triglycerides levels and increased SOD and glutathione peroxidase activities. It is a fact that limited studies on the effects of melatonin on hepatic steatosis have been performed so far.

Flavonoids are naturally occurring phenolic compounds, nearly ubiquitous in plants, and have long been recognized to possess antioxidant, hepatoprotective, anti-inflammatory, anti-allergic, antithrombotic, antiviral and anticarcinogenic activities (14) . Long ago, Afanas'ev at al (47) reported that quercetin is able to suppress free radical process at three stages: the formation of superoxide ion, the generation of hydroxyl (or cryptohydroxyl) radicals in the Fenton reaction and the formation of lipid peroxy-radicals. All flavonoids including quercetin were shown to be chelating agents capable of producing stable complexes with transition metal ions $\left(\mathrm{Fe}^{2+}, \mathrm{Fe}^{3+}, \mathrm{Cu}^{2+}\right)$. The cytoprotective effect of flavonoids is in strong positive correlation with their antiradical activity to $\mathrm{O}^{2-*}$ (48). Janbaz et al (49) showed that pre-treatment of rats with quercetin reduced the death rate to $30 \%$ by its hepatoprotective activity against $\mathrm{CCl}_{4}$ intoxication. We detected decreased numbers of TUNEL positive cells in quercetin administered group versus $\mathrm{CCl}_{4}$ administered group. It is clear that quercetin is beneficial against necrotic as well as apoptotic cell death. On the other hand, we suggest that decrease in the number of PCNA positive cells results in the improvement of inducing effect such as: oxidative stress rather than a failure in the proliferative capacity of hepatocytes. Several studies have found quercetin beneficial in non-alcoholic steatohepatitis by significantly decreasing lipoperoxidation, DNA damage, and histopathological alterations including macrovesicular steatosis, ballooning and inflammatory process $(50,51)$. Zhou et al (51) suggested that quercetin might be helpful to delay the progression of non-alcoholic fatty liver disease possibly by adjusting the balance of inflammatory cytokines including IL-18 and IL10. Vidyashankar et al (52) reported quercetin-induced increases in SOD, CAT and glutathione peroxidase activities in the culture media. We detected increases in the mean tissue CAT and SOD activities and significant increase in GSH level. Kobori et al (53) reported that chronic dietary intake of quercetin reduced liver fat accumulation associated with Western-style diet in mice and improved systemic parameters of metabolic syndrome, probably mainly through decreasing oxidative stress and reducing expression of genes related to steatosis.

As a conclusion, while quercetin seems to be more beneficial in reducing lipid peroxidation, melatonin seems to be more effective to support cellular antioxidant enzyme system. By the means of histopathological examination, we think that both agents are beneficial against necrotic and apoptotic cell death during steatosis. Nevertheless, we suggest that melatonin and quercetin might be beneficial in the improvement of hepatic steatosis, at least by supporting conventional therapy in humans.

\section{References}

1. Marra F, Gastaldelli A, Svegliati Baroni G, Tell G, Tiribelli C. Molecular basis and mechanisms of progression of non-alcoholic steatohepatitis. Trends Mol Med 2008; 14: 72-81.

2. El-Halawany AM, El Dine RS, El Sayed NS, Hattori M. Protective effect of Aframomum melegueta phenolics against $\mathrm{CCl}(4)$-induced rat hepatocytes damage; role of apoptosis and pro-inflammatory cytokines inhibition. Scientific Rep 2014; 4: 5880.

3. elSisi AE, Earnest DL, Sipes IG. Vitamin A potentiation of carbon tetrachloride hepatotoxicity: role of liver macrophages and active oxygen species. Toxicol Appl Pharmacol 1993; 119: 295-301.

4. Fouad FM, Mamer OA, Shahidi F. Acute-phase response in rat to carbon tetrachloride-azathioprine induced cirrhosis and partial hepatectomy of cirrhotic liver. J Toxicol Environ Health 1996; 47: 601-615.

5. Poli G, Albano E, Dianzani MU. The role of lipid peroxidation in liver damage. Chem Phys Lipids 1987; 45: 117-142.

6. Recknagel RO, Glende EA, Jr., Dolak JA, Waller RL. Mechanisms of carbon tetrachloride toxicity. Pharmacol Ther 1989; 43: 139-154.

7. Reiter RJ, Tan DX. Melatonin: a novel protective agent against oxidative injury of the ischemic/reperfused heart. Cardiovasc Res 2003; 58 : $10-19$.

8. Esrefoglu M, Gul M, Ates B, Batcioglu K, Selimoglu MA. Antioxidative effect of melatonin, ascorbic acid and $\mathrm{N}$-acetylcysteine on caerulein-induced pancreatitis and associated liver injury in rats. WJG 2006; 12: $259-264$.

9. Esrefoglu M, Gul M, Ates B, Yilmaz I. The ultrastructural and biochemical evidences of the beneficial effects of chronic caffeic acid pheneth$\mathrm{yl}$ ester and melatonin administration on brain and cerebellum of aged rats. Fund Clin Pharmacol 2010; 24: 305-315. 
10. Esrefoglu M, Gul M, Ates B, Erdogan A. The effects of caffeic acid phenethyl ester and melatonin on age-related vascular remodeling and cardiac damage. Fund Clin Pharmacol 2011; 25: 580-590.

11. Esrefoglu M, Iraz M, Ates B, Gul M. Melatonin and CAPE are able to prevent the liver from oxidative damage in rats: an ultrastructural and biochemical study. Ultrastruct Pathol 2012; 36: 171-178.

12. Rezzani R, Buffoli B, Rodella L, Stacchiotti A, Bianchi R. Protective role of melatonin in cyclosporine A-induced oxidative stress in rat liver. Internat Immunopharmacol 2005; 5: 1397-405.

13. Rezzani R, Rodella LF, Bonomini F, Tengattini S, Bianchi R, Reiter RJ. Beneficial effects of melatonin in protecting against cyclosporine A-induced cardiotoxicity are receptor mediated. J Pineal Res 2006; 41: 288-295.

14. Middleton E, Jr., Kandaswami C, Theoharides TC. The effects of plant flavonoids on mammalian cells: implications for inflammation, heart disease, and cancer. Pharmacol Rev2000; 52: 673-751.

15. Nijveldt RJ, van Nood E, van Hoorn DE, Boelens PG, van Norren K, van Leeuwen PA. Flavonoids: a review of probable mechanisms of action and potential applications. Amer J Clin Nutr 2001; 74: 418-425.

16. Bradford MM. A rapid and sensitive method for the quantitation of microgram quantities of protein utilizing the principle of protein-dye binding. Analyt Biochem1976; 72: 248-254.

17. Buege JA, Aust SD. Microsomal lipid peroxidation. Methods in enzymology 1978; 52: 302-310.

18. Akerboom TP, Sies H. Assay of glutathione, glutathione disulfide, and glutathione mixed disulfides in biological samples. Methods Enzymol 1981; 77: 373-382.

19. Luck H. Methods of Enzymatic Analysis. In, Verlag Chemie, New York: Academic Press, 1963.

20. McCord JM, Fridovich I. Superoxide dismutase. An enzymic function for erythrocuprein (hemocuprein). J Biol Chem 1969; 244: 6049-6055.

21. Upur H, Amat N, Blazekovic B, Talip A. Protective effect of Cichorium glandulosum root extract on carbon tetrachloride-induced and galactosamine-induced hepatotoxicity in mice. Food and chemical toxicology: an international journal published for the Brit Industr Biol Res Ass 2009; 47: 2022-2030.

22. Pierce RA, Glaug MR, Greco RS, Mackenzie JW, Boyd CD, Deak SB. Increased procollagen mRNA levels in carbon tetrachloride-induced liver fibrosis in rats. J Biol Chem 1987; 262: 1652-1658.

23. Hernandez-Munoz R, Diaz-Munoz M, Suarez J, Chagoya de Sanchez V. Adenosine partially prevents cirrhosis induced by carbon tetrachloride in rats. Hepatol (Baltimore) 1990; 12: 242-248.

24. Brattin WJ, Glende EA, Jr., Recknagel RO. Pathological mechanisms in carbon tetrachloride hepatotoxicity. J Free Radic Biol Med 1985; 1: $27-38$.

25. Singh N, Kamath V, Narasimhamurthy K, Rajini PS. Protective effect of potato peel extract against carbon tetrachloride-induced liver injury in rats. Environ Toxicol Pharmacol 2008; 26: 241-246.

26. Brent JA, Rumack BH. Role of free radicals in toxic hepatic injury. I. Free radical biochemistry. J Toxicol Clin Toxicol 1993; 31: 139-171.

27. Yahuaca P, Amaya A, Rojkind M, Mourelle M. Cryptic adenosine triphosphatase activities in plasma membranes of CCl4-cirrhotic rats. Its modulation by changes in cholesterol/phospholipid ratios. Lab Invest $\mathrm{J}$ Techn Methods Pathol 1985; 53: 541-545.
28. Muriel P. Nitric oxide protection of rat liver from lipid peroxidation, collagen accumulation, and liver damage induced by carbon tetrachloride. Biochem Pharmacol 1998; 56: 773-779.

29. Pereira CF, Oliveira CR. Oxidative glutamate toxicity involves mitochondrial dysfunction and perturbation of intracellular $\mathrm{Ca} 2+$ homeostasis. Neurosci Res 2000; 37: 227-236.

30. Ding WX, Nam Ong C. Role of oxidative stress and mitochondrial changes in cyanobacteria-induced apoptosis and hepatotoxicity. FEMS Microbiol Lett 2003; 220: 1-7.

31. Beddowes EJ, Faux SP, Chipman JK. Chloroform, carbon tetrachloride and glutathione depletion induce secondary genotoxicity in liver cells via oxidative stress. Toxicol 2003; 187: 101-115.

32. van Gurp M, Festjens N, van Loo G, Saelens X, Vandenabeele P. Mitochondrial intermembrane proteins in cell death. Biochem Biophys Med Comm 2003; 304: 487-497.

33. Liu YJ, Du JL, Cao LP, Jia R, Shen YJ, Zhao CY, Xu P, Yin GJ. Anti-inflammatory and hepatoprotective effects of Ganoderma lucidum polysaccharides on carbon tetrachloride-induced hepatocyte damage in common carp (Cyprinus carpio L.). Internat Immunopharmacol 2015; 25: $112-120$.

34. Fausto N. Liver regeneration. J Hepatol 2000; 32: 19-31.

35. Overturf K, al-Dhalimy M, Ou CN, Finegold M, Grompe M. Serial transplantation reveals the stem-cell-like regenerative potential of adult mouse hepatocytes. Amer J Pathol 1997; 151: 1273-1280.

36. Muller P, Felin R, Lambrecht J, Agostini B, Wieland H, Rost W, Seidel D. Hypertriglyceridaemia secondary to liver disease. Eur J Clin Invest 1974; 4: 419-428.

37. Jahn CE, Schaefer EJ, Taam LA, Hoofnagle JH, Lindgren FT, Albers JJ, Jones EA, Brewer HB, Jr. Lipoprotein abnormalities in primary biliary cirrhosis. Association with hepatic lipase inhibition as well as altered cholesterol esterification. Gastroenterol 1985; 89: $1266-1278$.

38. Havel RJ. Functional activities of hepatic lipoprotein receptors. Ann Rev Physiol 1986; 48: 119-134.

39. Sahreen S, Khan MR, Khan RA. Hepatoprotective effects of methanol extract of Carissa opaca leaves on CCl4-induced damage in rat. BMC Compl Alter Med 2011; 11: 48.

40. Halliwell B, Gutteridge JM. Oxygen toxicity, oxygen radicals, transition metals and disease. Biochem J 1984; 219: 1-14.

41. Daniel RS, Mathew BC, Devi KS, Augusti KT. Antioxidant effect of two flavonoids from the bark of Ficus bengalensis Linn in hyperlipidemic rats. Ind J Exp Biol 1998; 36: 902-906.

42. Liu F, Ng TB. Effect of pineal indoles on activities of the antioxidant defense enzymes superoxide dismutase, catalase, and glutathione reductase, and levels of reduced and oxidized glutathione in rat tissues. Biochem Cell Biol 2000; 78: 447-453.

43. Talu MF, Gul M, Alpaslan N, Yigitcan B. Calculation of melatonin and resveratrol effects on steatosis hepatis using soft computing methods. Comp Methods Programs Biomed 2013; 111: 498-506.

44. Kus I, Ogeturk M, Oner H, Sahin S, Yekeler H, Sarsilmaz M. Protective effects of melatonin against carbon tetrachloride-induced hepatotoxicity in rats: a light microscopic and biochemical study. Cell Biochem Funct 2005; 23: 169-174. 


\section{7-354}

45. Hatzis G, Ziakas P, Kavantzas N, Triantafyllou A, Sigalas P, Andreadou I, Ioannidis K, Chatzis S, Filis K, Papalampros A, Sigala F. Melatonin attenuates high fat diet-induced fatty liver disease in rats. World J Hepatol 2013; 5: 160-169.

46. Pan M, Song YL, Xu JM, Gan HZ. Melatonin ameliorates nonalcoholic fatty liver induced by high-fat diet in rats. J Pineal Res 2006; 41 : 79-84.

47. Afanas'ev IB, Dorozhko AI, Brodskii AV, Kostyuk VA, Potapovitch AI. Chelating and free radical scavenging mechanisms of inhibitory action of rutin and quercetin in lipid peroxidation. Biochem Pharmacol 1989; 38: 1763-1769.

48. Potapovich AI, Kostyuk VA. Comparative study of antioxidant properties and cytoprotective activity of flavonoids. Biochem Biokh 2003; 68: 514-519.

49. Janbaz KH, Saeed SA, Gilani AH. Studies on the protective effects of caffeic acid and quercetin on chemical-induced hepatotoxicity in rodents. Phytomedi 2004; 11: 424-430.
50. Marcolin E, Forgiarini LF, Rodrigues G, Tieppo J, Borghetti GS, Bassani VL, Picada JN, Marroni NP. Quercetin decreases liver damage in mice with non-alcoholic steatohepatitis. Basic Clin Pharmacol Toxicol 2013; 112: 385-391.

51. Zhou DS, Liang ZQ, Qin Q, Zhang MH, Li SL. (Therapeutic efficacy and mechanisms of quercetin in a rat model of nonalcoholic fatty liver disease). Zhonghua gan zang bing za zhi (Chinese J Hepatol) 2013; 21: 134-137.

52. Vidyashankar S, Sandeep Varma R, Patki PS. Quercetin ameliorate insulin resistance and up-regulates cellular antioxidants during oleic acid induced hepatic steatosis in HepG2 cells. Toxicology in vitro: an international journal published in association with BIBRA 2013; 27: 945-953.

53. Kobori M, Masumoto S, Akimoto Y, Oike H. Chronic dietary intake of quercetin alleviates hepatic fat accumulation associated with consumption of a Western-style diet in C57/BL6J mice. Mol Nutr Food Res 2011; 55: 530-540. 